\title{
ESCOLHA E PERMANÊNCIA NO CURSO SUPERIOR: VOZES DE ESTUDANTES DO PROGRAMA VESTIBULAR SOCIAL DA PUC - GOIÁS
}

Students from the social "vestibular" entrance exam program in higher education: from program choice to retention

\author{
Gilza Carla Temoteo Melo ${ }^{1}$
}

Cláudia Valente Cavalcante ${ }^{2}$

Marcelo Almeida de Camargo Pereira ${ }^{3}$

\begin{abstract}
RESUMO: este artigo, resultado de uma pesquisa de mestrado em Educação, tem como objetivo discutir a escolha do curso superior por estudantes beneficiários do Programa Vestibular Social da Pontifícia Universidade Católica de Goiás na Universidade. O Programa foi implementado em 2010 tendo entre os seus objetivos possibilitar a inserção de estudantes de camadas populares na Educação Superior. A pesquisa aponta que os jovens bolsistas do Vestibular Social demonstraram incertezas na escolha do curso. Quanto à permanência, as principais dificuldades apresentadas foi a financeira, de aprendizagem e conciliar trabalho e estudo. Também encontramos que maioria dos estudantes beneficiários do Programa Vestibular Social são oriundos da Educação Básica pública e muitos pertencem a primeira geração familiar a cursar o nível superior.
\end{abstract}

Palavras-chave: Educação Superior. Estudantes. Programa Vestibular Social. Escolha do Curso.

\begin{abstract}
The goal of this article, the result of a master's research study in Education, is to discuss the decision to enter higher education by students benefiting from the Social "Vestibular" Entrance Exam Program at the Pontifical Catholic University of Goiás. The Program was implemented in 2010 with one of its goals being to facilitate the inclusion of students from lower classes into Higher Education. This research indicates that the young scholarship holders from the Social Entrance Exam Program expressed uncertainties when choosing the program. Regarding retention, the main difficulties they had involved finances, learning, and reconciling work and studies. We also found that the majority of students benefiting from the Social Entrance Exam Program were from public Basic Education and many were the first generation in their family to attend higher education.
\end{abstract}

Keywords: Higher Education. Students. Social "Vestibular" Entrance Exam Program. Program Choice.

1 Mestre em Educação. Especialista em Análise e Diagnóstico Organizacional. Coordenadora acadêmicoadministrativa na Pontifícia Universidade Católica de Goiás , vinculada a Pró Reitoria de Graduação. E-mail :gilza@pucgoias.edu.br ;

${ }^{2}$ Doutora e Mestre em Educação pela PUC Goiás. Professora e vice-coordenadora do Programa de Pós-graduação em Educação e do curso de Pedagogia da Pontifícia Universidade Católica de Goiás. E-mail: cavalcante.70@ hotmail.com;

3 Doutor E Mestre em Educação pela Universidade La Salle. Analista de Correios - Administrador. E-mail: marceloacpereira@gmail.com 


\section{INTRODUÇÃO}

A partir de 1990 o Brasil, acompanhando o movimento internacional, adere aos processos de consolidação do neoliberalismo, dando início às reformas das políticas públicas e o campo da Educação Superior começa a ser redesenhado, com a criação de instituições, cursos, turnos, modalidades curriculares que ocasionaram o aumento de ingressantes para esse nível de escolarização, assim como o aumento no número de Instituições de Educação Superior - IES, sobretudo, as privadas.

Diante desse crescimento e para atender o Plano Nacional de Educação, instituído para o período de 2014 a 2024, reafirmou o princípio da democratização da Educação Superior e estabeleceu a meta 12: "elevar a taxa bruta de matrícula na educação superior para 50\% e a taxa líquida para 33\% da população de 18 a 24 anos, assegurando a qualidade da oferta" (BRASIL, 2001). Com isso o Estado e as IES privadas, com ou sem fins lucrativos, criaram várias políticas de inclusão que são voltadas a inclusão dos estudantes de baixa renda na Educação Superior.

Sabe-se que as políticas e os programas de inclusão não são a garantia de continuidade dos estudos, visto que estudantes bolsistas também evadem da Educação Superior (FELICETTI, 2011; FELICETTI e FOSSATTI, 2014; GOMES, 2015; NALIN, 2018). A evasão se dá, pois, muitos estudantes enfrentam obstáculos que dificultam a sua permanência, dentre eles: estudantes pertencentes às famílias desprovidas de capital econômico e cultural, marcados por uma trajetória escolar com déficits de conteúdos e habitus escolar ou ainda a escolha do curso.

Parte-se do pressuposto que o acesso a este grau de ensino não é a única garantia de permanência do jovem estudante que almeja entrar em uma universidade, visto que a origem social é uma interface considerável na trajetória escolar dos estudantes beneficiários por políticas e programas sociais de inclusão. O jovem estudante da Educação Superior de instituições privadas ou comunitárias é, na sua maioria das camadas populares, trabalhador com renda de até três salários mínimos, que passa dificuldade no sustento da família e no custeio da vida universitária. Oriundo de escolas públicas, que enfrentam o descompasso intelectual das classes médias que vêm de escolas onde o nível de escolarização é considerado mais elevado.

A Educação Superior, como espaço de inclusão social, propõe pensar a diferença como uma marca humana, presente em todas as situações sociais e, consequentemente, em todas as salas de aula, nas diversas modalidades de ensino e realidades socioculturais. De acordo com Mantoan (2003, p. 192): “as diferenças são produzidas e não devem ser naturalizadas, como pensamos habitualmente. Essa produção é sustentada por relações de poder e merece ser compreendida, questionada e não apenas respeitada e tolerada". O direito de todos à educação, independentemente 
de origens étnicas, sociais e religiosas, deve ser o princípio básico de qualquer debate sobre inclusão social na universidade.

Há uma preocupação em relação ao acesso, mas o que tem sido amplamente discutido também é a questão da permanência na universidade. Severino (2003, p. 124) enfatiza: “a democratização do acesso e da permanência nas IES tem sido aspiração de largas camadas da sociedade". De acordo com Zago (2006) uma efetiva democratização da educação requer certamente políticas para a ampliação do acesso e fortalecimento do ensino público, em todos os seus níveis, mas requer também políticas voltadas para a permanência dos estudantes no sistema educacional de ensino.

Vale destacar que as IES têm papel importante em relação à permanência dos alunos quando considerada a infraestrutura ofertada, como moradia estudantil, apoio ao transporte, biblioteca, refeitório, apoio para estudantes com deficiência física, apoio acadêmico pedagógico, entre outros. Para autores como Tinto (1993), a permanência do estudante na Educação Superior é bastante influenciada pela integração ao ambiente social e acadêmico, além de estar associada ao nível de expectativas do aluno. Ou seja, "quanto maior o comprometimento do aluno com a instituição e com os seus próprios objetivos, e elevado for o nível de integração acadêmica e social desse aluno, menor a probabilidade de evasão" (TINTO, 1993, p.130).

Além disso, há outros fatores que intervém na permanência na universidade até a sua integralização. A escolha do curso, segundo Lloyd (2008), caracteriza-se como um fator crítico para o sucesso do estudante na faculdade. Para ele, a escolha do curso não pode estar apenas relacionada com o desejo da graduação, mas também com as afinidades e habilidades que os estudantes têm para seguirem na profissão escolhida. Tinto (2012) também aponta a questão da escolha do curso e encontra em suas pesquisas que muitos estudantes iniciam um curso superior sem ter noção da relação entre suas características individuais e as do curso escolhido.

Como uma das formas de mitigar o problema do acesso e da continuidade nos estudos, a Pontifícia Universidade Católica de Goiás, instituição de Educação Superior privada, filantrópica, comunitária e confessional, inserida no Estado de Goiás há 59 anos, vem ofertando aos seus estudantes bolsas e financiamentos próprios. Dentre eles, salienta-se o Programa Vestibular Social, instituído no ano de 2010 com objetivo de atender a inserção de estudantes das camadas populares à Educação Superior em diferentes cursos de licenciatura e em Serviço Social.

Com isso, o objetivo principal desta pesquisa foi evidenciar um ponto importante na permanência do estudante jovem que ingressa na Pontifícia Universidade Católica de Goiás por meio do Programa do Vestibular Social, com foco nos processos de estratégia de permanência e na escolha do curso pelo estudante. 
Na sequência do artigo apresentamos o Programa Vestibular Social, a metodologia atinente a este artigo, a análise do corpus, as considerações finais e as referências que permearam este estudo.

\section{PROGRAMA VESTIBULAR SOCIAL NA PUC - GOIÁS}

Na década de 2010 ocorreu um declínio na procura dos cursos voltados para a formação de professores, a baixa procura por esses cursos, têm contribuído para a carência deste profissional, principalmente nas áreas exatas e de ciências da natureza. De acordo com um estudo do Movimento Todos pela Educação, que teve como base dados do Instituto Nacional de Estudos e Pesquisas Educacionais Anísio Teixeira (Inep), a cada 100 jovens que ingressam em licenciaturas ou cursos de pedagogia, somente 51 concluem as graduações. Além disso, o levantamento identificou que entre esses alunos que terminam os cursos, apenas 27 demonstram interesse em seguir na profissão de professor (SANTOS, 2018).

Nos últimos anos, os índices decadentes reiteram que estudantes brasileiros estão evitando a formação docente na hora de se inscrever para as seleções de universidades públicas e privadas. De acordo com a pesquisa do Sindicato das Mantenedoras de Ensino Superior (Semesp), entre 2010 e 2016, a quantidade de alunos que entraram em cursos de licenciatura caiu 10\%. O levantamento ainda aponta que só 39,5\% dos formados em licenciatura continuaram trabalhando na área (CRAIDE, 2018).

A PUC Goiás incluída neste cenário, em 2010 constitui o Programa Vestibular Social, que nasce com o objetivo de alcançar uma proposta fundamentada tanto no ponto de vista financeiro, pois era uma forma de diminuir a evasão nos cursos de licenciatura, quanto do ponto de vista social.

Segundo os autores:

En este sentido, el Examen Vestibular Social, al mismo tiempo que se contrapone a
un discurso de sentido común que etiqueta a sus alumnos ingresantes como
"económicamente desfavorecidos", "socialmente incapaces" o "diferentes", busca
reairmarlos como política institucional que articula el ingreso, la permanencia y la
conclusión con calidad. Están en discusión en este proyecto la comprensión de que el
conocimiento es un bien común, por lo tanto, debe ser producido y compartido por
todos, así como estar al servicio de la vida en todas sus dimensiones: ética, estética,
humana, política, económica, cultural, entre otras. En ese sentido, en el Examen
Vestibular Social se entiende que el ingreso a la universidad es una posibilidad de
democratización al acceso al conocimiento que es históricamente producido por todos
(CARVALHO; SIQUEIRA, 2015, p. 199).

Para inserção do mesmo, deu-se envolvimento de diversas Pró-reitorias e dos coordenadores dos cursos de licenciaturas. A Pró-reitoria de administração realizou o levantamento de custos e o estudo sobre o impacto financeiro do programa. A Pró-reitoria de Desenvolvimento 
Institucional, fez análise sobre a carga horária docente e sobre o trabalho dos funcionários das secretarias nessa nova projeção de expansão. A Pró-reitoria de Graduação analisou a disponibilidade da infraestrutura acadêmica (equipamentos, salas de aula, laboratórios, capôs de estágios), contratação docente, avaliação sobre medidas de superação de defasagem escolar dos acadêmicos. Os coordenadores dos cursos de licenciatura e Serviço Social reorganizaram os espaços e horários (AMADO, 2019).

A Sociedade Goiana de Cultura mantenedora da PUC Goiás, aprova o Programa Vestibular Social, baseado na Lei $n^{\circ} 12.101$, de 27/11/2009, alterada pela Lei $n^{\circ} 12.868$, de 15/10/2013, no Decreto No 8.242, de 23/5/2014, nas respectivas regulamentações e nas diretrizes institucionais da PUC Goiás.

A PUC Goiás é uma universidade de natureza jurídica confessional, católica, comunitária, filantrópica, pluridisciplinar e sem fins econômicos, para formação de quadros profissionais de nível superior, em ensino, pesquisa, extensão. Pela filantropia, ela tem a isenção de impostos (20\% sobre o seu orçamento anual) e em contrapartida, na forma de lei, aplicou esse recurso financeiro nas ações comunitárias e em bolsas de filantropia. (AMADO, 2019).

Mesmo diante desta opção estatutária, segundo o reitor:

O Vestibular Social não foi implantado em razão da filantropia, nem em razão da concessão do $\mathrm{CEBAS}^{4}$. Entretanto, logo se tornou um programa institucional de inclusão de estudantes de baixa renda, mantido sob a renúncia de receita da Universidade e incorporado ao conjunto das várias formas de acesso. A esse programa se acrescentou o PIBID e, para muitos, a Bolsa Universitária OVG, garantindo e aumentando os índices de permanência dos estudantes de baixa renda (AMADO, 2019).

Partindo dessa premissa, diferentemente de outros programas de bolsa ofertados pela instituição o Vestibular Social não se configura pela sua natureza jurídica. O Programa no primeiro semestre de 2010 ofertou vagas para o curso de Serviço Social e todas as Licenciaturas: Biologia, Educação Física, Filosofia, Física, Geografia, História, Letras, Matemática, Pedagogia e Química.

O Programa Vestibular Social foi realizado no primeiro semestre de 2010, voltado ao ingresso de estudantes de camadas populares na PUC Goiás, propõe-se com o programa conceder bolsas de estudos parciais a estudantes de baixa renda, em cursos de graduação e sequenciais de

\footnotetext{
${ }^{4}$ Certificação de Entidades Beneficentes de Assistência Social na Área de Educação (CEBAS), O MEC, por intermédio da Secretaria de Regulação e Supervisão da Educação Superior - SERES, é responsável pela certificação das entidades beneficentes de assistência social que tenham atuação exclusiva ou preponderante na área da educação, conforme disposto na Lei no 12.101, de 27 de novembro de 2009. art. 1 A certificação das entidades beneficentes de assistência social e a isenção de contribuições para a seguridade social serão concedidas às pessoas jurídicas de direito privado, sem fins lucrativos, reconhecidas como entidades beneficentes de assistência social com a finalidade de prestação de serviços nas áreas de assistência social, saúde ou educação, e que atendam ao disposto nesta Lei.
} 
formação específica. Para candidatos com renda familiar per capita até 1,5 salários-mínimos, foi oferecida bolsa de $80 \%$; e para candidatos com renda familiar per capita acima de 1,5 até 2,5 salários mínimos, foi oferecida bolsa de $50 \%$.

A partir do segundo semestre de 2010, após avaliação da experiência do primeiro semestre e para compatibilizar com os critérios do Programa Universidade Para Todos (PROUNI), foram oferecidas bolsas de 50\% aos candidatos com renda bruta familiar de até seis salários mínimos, ou com renda bruta de até dois salários mínimos, no caso em que o grupo familiar se restrinja ao próprio candidato. Desde que esse processo seletivo foi implementado, o candidato aprovado, mesmo que não tenha o perfil socioeconômico exigido, ele continua a ter direito à vaga, sem o benefício da bolsa e pode matricular-se pagando o valor integral da mensalidade.

O estudante beneficiado pode complementar os 50\% da mensalidade agregando o FIES, Organização das Voluntárias de Goiás - OVG, Programa Institucional de Bolsas de Iniciação à Docência (PIBID), o Programa sem fronteira (governamental) e o Programa de Bolsa Santander (convênio).

No Vestibular Social do segundo semestre de 2010, em função da baixa demanda de alguns cursos de graduação foi inserido no programa cursos de Bacharelado, tais como: Fonoaudiologia, Direito, Ciências Contábeis, Engenharia de Computação para preenchimento de vagas no turno vespertino em que a instituição estava com pouca ocupação e a baixa demanda. Os cursos de Jornalismo, Arqueologia e Teologia a oferta de vagas foi no noturno. No segundo semestre de 2011, foi incluído o curso de Bacharelado em Biologia e no primeiro semestre de 2012, foi incluído o curso de Ciências Econômicas. O processo seletivo Vestibular Social é composto de duas provas, sendo uma prova objetiva, com 20 questões de múltipla escolha e outra prova de Redação em Língua Portuguesa. A partir de 2011/2 as provas passaram a ser elaboradas com questões diferentes do processo seletivo tradicional.

$\mathrm{Na}$ atualidade existe duas modalidades de ingresso: Modalidade I o candidato concorrerá a vaga utilizando as notas do Exame Nacional do Ensino Médio, desde que o candidato tenha nota igual o superior a quatrocentos pontos e na redação nota mínima de trezentos pontos; Modalidade II onde o candidato fará provas aplicadas pela PUC Goiás, utilizando as notas obtidas por ele na avaliação por área de conhecimento e Redação em Língua Portuguesa. Quanto aos critérios para concessão da bolsa, possuir renda familiar de até um salário mínimo e meio por pessoa, apresentar patrimônio compatível com a renda familiar do candidato; não ser portador de diploma de curso superior e não estar matriculado em qualquer curso de graduação e pós-graduação. No que tange a perda do benefício, o estudante não pode mudar de turno; fazer reopção de curso; possuir 
rendimento acadêmico inferior a $75 \%$ nas disciplinas cursadas no semestre; alteração do perfil socioeconômico.

Após dois anos de implementação do vestibular social, a PUC Goiás realizou um levantamento detalhado para conhecer o jovem ingressante do programa, 380 estudantes responderam o questionários, destes $60 \%$ são do sexo feminino e $64,73 \%$ com faixa etária de idade abaixo de 25 anos , 49,47\% se consideram pardo, 70\% concluíram o ensino médio em escola pública e a jornada de trabalho dos jovens ingressantes pelo vestibular social se difere dos demais jovens da instituição que ingressam pelo vestibular tradicional.

Atualmente, 26 cursos ofertam vagas no vestibular social. Na Tabela 1 abaixo nota-se que desde a criação do programa, o percentual de matriculas na universidade na condição de bolsista do Vestibular Social, teve aumento ano a ano. Observa-se que no ano de 2018 houve um declínio no número de matrículas no computo geral, devido a variáveis da situação política financeira que atingi o País. No entanto, se levarmos em consideração os matriculados pelo Vestibular Social em 2018, estes, corresponderam a 32\% do total de matriculados na instituição, ou seja, a quantidade de bolsista aumentou desde a sua criação. Essa expansão também se deve ao aumento de vagas e cursos ofertados.

Tabela 1: Matriculados no vestibular tradicional e social 2010 a 2018.

\begin{tabular}{lccc}
\hline Ano & $\begin{array}{c}\text { Estudantes } \\
\text { Matriculados na } \\
\text { Instituição }\end{array}$ & $\begin{array}{c}\text { Estudantes } \\
\text { Matriculados no } \\
\text { Vestibular Social }\end{array}$ & \% \\
\hline 2010 & 21.942 & 826 & $4 \%$ \\
2011 & 22.551 & 1.941 & $9 \%$ \\
2012 & 23.700 & 3.042 & $13 \%$ \\
2013 & 24.792 & 4.216 & $17 \%$ \\
2014 & 25.695 & 5.333 & $21 \%$ \\
2015 & 24.757 & 6.083 & $25 \%$ \\
2016 & 25.122 & 6.499 & $26 \%$ \\
2017 & 23.593 & 6.589 & $28 \%$ \\
2018 & 21.054 & 6.779 & $32 \%$ \\
\hline
\end{tabular}

Fonte: Tabela elaborada a partir dados da PUC Goiás. 
Sobre a importância social do programa, o Reitor na entrevista faz uma análise de que "além da dimensão político administrativa, há subjacente uma opção política mais ampla, de compromisso social e de contribuição para superar as profundas desigualdades de nosso país; e uma opção ética, onde o direito, a justiça e a equidade dentro de nossas possibilidades e limitações de recursos, não são apenas princípios e valores, mas tomam corpo histórico, sinalizam o testemunho de vida e se configuram em identidade institucional.”(AMADO, 2019).

O programa do Vestibular Social até o ano de 2019 diplomou 4.056 estudantes tornou-se um programa de inclusão de grande importância para instituição e, principalmente, para a sociedade. Diante do objetivo do programa, ressalta-se que programa não tem sido a garantia de permanência nos cursos de licenciatura.

Mas frente a conjuntura do país em que há uma crise e desvalorização da educação, a permanência material e simbólica é um desafio constante para o estudante de cursos de licenciatura e, institucionalmente, isso significa revisitar as ações e estratégias para a não evasão dos estudantes e a conclusão do curso com êxito.

\section{METODOLOGIA}

Este estudo caracterizou-se como um estudo do tipo qualitativo que realizou entrevista com oito estudantes beneficiados com bolsa do Programa Vestibular Social da Pontifícia Universidade Católica de Goiás. A pesquisa qualitativa permite um tipo de discussão teórica e metodológica que é própria das ciências humanas, uma vez que seu campo de atuação, segundo Martins (1989), não é predelineado. Abrange, além da vertente educacional e os demais alcances do conhecimento da vida humana, aspectos como linguagem e relações sociais.

A análise aqui apresentada, do corpus formado das entrevistas realizadas, é parte de uma pesquisa maior, ou seja, os oito entrevistados foram eleitos de um universo de 120 respondentes ao questionário enviado para 481 bolsistas do Vestibular Social. Os critérios de escolha dos oito estudantes para a entrevista foram: estar matriculado no curso das escolas com maior número de bolsistas do programa nas 07 Escolas e 01 Instituto da PUC Goiás, a saber: Escola de Gestão e Negócios, Instituto Goiano de Pré-história e Antropologia (IGPA), Escola de Ciências Sociais e da Saúde, Escola de Formação de Professores e Humanidades, Escola de Ciências Exatas e da Computação , Escola de Ciências Agrárias e Biológicas, Escola de Direito e Relações Internacionais e Escola de Comunicação. dos cursos de Administração, Arqueologia, Ciências Biologica, Ciência da Computação, Direito, Enfermagem, Jornalismo e Pedagogia. Os depoimentos dos entrevistados 
constarão em itálico ao longo do artigo e serão denominados por nomes fictícios: $R 1, R 2, R 3, R 4$, R5, R6, R7 e R8.

As perguntas das entrevistas eram compostas de questões sobre acesso na universidade, a escolha do curso, processos de permanência, perspectivas de futuro e a experiência dos estudantes na universidade.

Neste trabalho nos dedicaremos a explorar aspectos relacionados à escolha do curso e a permanência dos estudantes na Educação Superior. Os estudantes assinaram o Termo Livre de Consentimento (TCLE) e o anonimato deles é garantido, tendo sua identidade preservada por meio de nomes fictícios, mantendo a ética de todo o processo de investigação e divulgação dos resultados.

\section{JOVENS DO VESTIBULAR SOCIAL: O QUE DADOS EXPRESSAM SOBRE SUAS IDENTIDADES?}

Dentro do quadro dos beneficiários do Programa do Vestibular Social, a grande parte constitui-se de jovens, esses representam 80\%. Para retratar o perfil desses jovens, e conhecer sua trajetória escolar desde a escolha do curso ao ingresso na universidade por meio do Programa, foi aplicado questionário que traça o perfil socioeconômico dos jovens do vestibular social.

Tabela 2: Perfil sociocultural dos respondentes do questionário da pesquisa.

\begin{tabular}{|c|c|c|c|c|c|}
\hline Quesito & Dado & & & & \\
\hline \multirow{2}{*}{ Gênero } & $73,61 \%$ & $26,39 \%$ & & & \\
\hline & masculino & masculino & & & \\
\hline \multirow{2}{*}{ Estado Civil } & $81,7 \%$ & $18,3 \%$ & & & \\
\hline & solteiros & casados & & & \\
\hline \multirow{2}{*}{ Filhos } & $88,3 \%$ & $11,7 \%$ & & & \\
\hline & Não & Sim & & & \\
\hline Local de & $86,73 \%$ & & & & \\
\hline Residência & Goiânia & & & & \\
\hline Moradia & $\begin{array}{c}55 \% \\
\text { própria }\end{array}$ & $\begin{array}{c}28 \% \\
\text { alugado }\end{array}$ & $\begin{array}{l}12,4 \% \\
\text { cedida }\end{array}$ & $\begin{array}{c}2,4 \% \\
\text { moradia } \\
\text { financiada }\end{array}$ & $\begin{array}{c}2,2 \% \\
\text { casa do } \\
\text { estudante }\end{array}$ \\
\hline Raça & $54,3 \%$ & $35,4 \%$ & $9,4 \%$ & $0,9 \%$ & \\
\hline
\end{tabular}




\begin{tabular}{ccccc} 
& pardos & brancos & preto & não \\
& & & respondeu \\
Transporte & $60,3 \%$ & $29,9 \%$ & $9,8 \%$ & \\
& público & carro & outros meios de \\
& transporte & \\
Necessidade & $98,3 \%$ nenhum & tipo de & 1,7\% não & \\
Especial & necessidade & responderam & \\
& & & \\
\hline
\end{tabular}

Fonte: Dados da pesquisa de campo (MELO,2018)

Com relação a escolha do curso, 64,7\% disseram que foi por vocação e realização pessoal, $16,8 \%$ por conta da boa remuneração, $11,8 \%$ outros e $6,7 \%$ não informaram. A escolha do curso dos estudantes das camadas populares tem demonstrado associação com a origem social, ou seja, entre a posição que os indivíduos ocupam na hierarquia social e o peso dos capitais social, econômico e cultural, herdados de suas famílias. (ZAGO,2005).

Quando perguntados sobre as maiores dificuldades de permanência no curso as mais citadas foram a financeira com 70,6\%,13,3\% falta de tempo, $0,8 \%$ saúde, $10,2 \%$ dificuldades de aprendizagem, 4,3\% o acesso, 0,8\% problemas pessoais (psicológicos, falecimento, distância, falta de incentivo da instituição e possui filhos).

\section{ESTUDANTES E A ESCOLHA DO CURSO}

Neste tópico é apresentada a caracterização dos oito entrevistados e a percepção deles acerca da escolha do curso. Entre os oito entrevistados, seis eram os primeiros do núcleo familiar

R1, jovem tímido de poucas palavras, é estudante do curso de Arqueologia, e está com vinte e dois anos, é natural de Goiânia, mas mora em Senador Canedo, cidade circunvizinha da capital do Estado de Goiás. Quanto à sua escolarização, deu-se toda em escola pública. O jovem não teve influência quanto a escolha do curso, tinha a consciência que deveria fazer ensino superior, não importava qual o curso: "Não gosto muito do curso, escolbi esse porque foi o que mais me atraiu, não tinha vocação para nada, mas sabia que tinha que fazer alguma coisa" (ENTREVISTA, R1, 2019).

$\mathrm{R} 2$, jovem inquieta e com vontade de falar sobre tudo que permeou os quatro anos de universidade, é estudante de Administração com vinte e um anos. O único vestibular que prestou 
foi na PUC Goiás, "a escolha pelas IES foi por acaso, iria prestar vestibular para primeira universidade que tivesse informação, logo que vi na televisão a propaganda do vestibular social, resolvi fažer" (ENTREVISTA R2, 2019).

Quanto à escolha do curso se deu por acreditar que iria proporcionar ascensão ao mercado de trabalho e por ter vontade de montar uma empresa. A escolha do curso não foi influenciada por ninguém: "Meu pai acha que o ensino superior não dá empregabilidade, não me apoia em nada. Minha mãe sabe que é importante estudar, mas se eu não quiser fažer faculdade ela não se incomoda" (ENTREVISTA R2, 2019).

R3, jovem determinada e séria, de 20 anos de idade, é natural de Goiânia e estudante do curso de Ciências Biológicas. Oriunda de escola pública, sempre viu no ensino superior uma oportunidade de futuro. A escolha do curso foi por gostar dessa área e por influência do mercado de trabalho. Ao término do ensino médio sabia da necessidade de dar continuidade aos estudos.

R4 é estudante de Ciência da Computação, com vinte e quatro anos. Sua escolarização se deu toda em escola pública. Natural de Osasco, no Estado de São Paulo, veio morar em Goiânia ainda criança. Atualmente, reside em Senador Canedo, cidade que fica a 23,5 Km de Goiânia. A escolha do curso foi por curiosidade: "analisei e investiguei e resolvi fazer esse curso" (ENTREVISTA R4, 2019).

R5, jovem autêntica e forte, é estudante de Direito, preta, natural de Goiânia, reside em Aparecida de Goiânia e está com 22 anos. Cursou o ensino fundamental em escola privada e o ensino médio na pública. Desde nova sabia qual seria a sua profissão, "pra mim é a realização de um sonho estudar Direito na PUC Goiás, sempre tive vocação e é uma grande realização profissional. Não tive nenhuma influência familiar, eles já tinham a consciência do que eu queria" (ENTREVISTA R5, 2019).

R6, estudante de Enfermagem, com vinte e um anos; é uma jovem simpática e tímida. Natural de Goiânia, seus estudos foram parte em escola pública e particular. Sente-se angustiada por está finalizando um curso que foi escolhido pela sua mãe: "Minha primeira opção era matemática, queria fazer licenciatura. Ai a gente decidiu fazer enfermagem. Eu e minha mãe (risos meio sem graça), quando passei no vestibular para licenciatura matemática fui toda feliz contar, minha mãe me disse que eu não ia fazer esse curso, porque ela havia feito licenciatura e não tinha uma boa rentabilidade financeira. Como eu era menor de idade, não podia assinar meus documentos, resolvi fazer o que ela queria” (ENTREVISTA R6, 2019).

R7, jovem questionadora e comunicativa, com 20 anos de idade. É estudante do curso de Jornalismo, cursou o ensino básico e médio em escola pública, mora em Senador Canedo e a distância da universidade é uma grande dificuldade para estudar. Ainda cursando o ensino médio prestou vestibular na PUC Goiás como trainee para ver como era o processo de avaliação, quando concluiu o ensino médio realizou vestibular na mesma instituição e foi aprovada. O curso foi 
escolhido por opção, adorava assistir jornal e sempre foi muito comunicativa: "realização de um sonho, sempre me identifiquei com essa área" (ENTREVISTA R7, 2019).

R8, estudante de Pedagogia, jovem determinada e expansiva, é parda e está com 23 anos. É natural de Pontalina, no estado de Goiás, e reside em Aparecida de Goiânia. Sua trajetória escolar antes de entrar na Universidade foi toda em escola pública. Chegou a estudar um ano de Direito em outra IES privada, mas não se identificou com o curso e a Universidade, "muito atacadista, tinha 120 alunos por sala e não gostava muito de estudar, matava muita aula". Logo ficou sabendo da possibilidade de estudar com bolsa pelo programa vestibular social e realizou vestibular na PUC Goiás para o curso de Pedagogia, algo que causou uma grande revolta por parte do pai que se manifestou em não a ajudar a custear o curso escolhido. "Meu pai ficou desapontado com a minha escolba, falava que en ia passar minha vida trocando fralda de criança o resto da vida, jamais pagaria um curso desse para mim. Ficou bem nítido que para ele o curso não tinha ascensão social" (ENTREVISTA R8, 2019).

No grupo dos jovens pesquisados, em suas singularidades, as histórias se entrecruzam nos aspectos referentes à origem social, à escolarização, à família e escolha do curso. De forma geral, percebe-se, neste estudo que a escolarização desses jovens é uma trajetória que não apresenta descontinuidades que grande parte estudou em escola pública, o que lhes possibilitou o acesso à universidade dentro da faixa etária de 18 a 24 anos que é a esperada e sugerida pelas políticas educacionais (PNE).

A escolha do curso para alguns estudantes e pelos pais não era relevante, o importante era fazer um curso superior. Outros jovens estudantes da pesquisa tiveram confronto com os pais, como é o caso da R8 que escolheu Pedagogia e não teve o apoio do pai e a R6 que aceitou a escolha da mãe em fazer Enfermagem e que se sente angustiada, pois sua opção era a licenciatura em Matemática. Os cursos concernentes à área do magistério são considerados "não de prestígio social" não os possibilitariam à reclassificação social e econômica. Em ambos os casos, fica evidenciada a importância que a família dá ao capital social, econômico e cultural. No caso desses, Bourdieu (2010) explica que o capital cultural se constitui o elemento da herança familiar que mais tem impacto na definição do destino escolar, visto que favorece o desempenho escolar na medida em que facilitaria a aprendizagem de conteúdo, dos códigos veiculados e sancionados pela escola. Por conta dessas trajetórias marcadas pelo baixo capital cultural herdado e institucionalizado, mas com alto nível de aspiração desses jovens em relação ao prolongamento da escolarização. $\mathrm{O}$ investimento escolar parental e as redes de sociabilidade durante o percurso escolar e social possibilitaram aos jovens a criação de estratégias que lhes permitiram desenvolver o senso prático do vestibular e ingressar na universidade. 
A escolha do curso pelos jovens, segundo Resende, Nogueira e Viana (2013), em sua aparência imediata, parece ser definida pelos próprios indivíduos em virtude de suas percepções sobre si e sua capacidade intelectual, habilidades, valores e interesses particulares, como gosto, vocação, expectativas (no caso, estabilidade, retorno financeiro, prestígio) e informações acerca do sistema universitário, dos cursos e das profissões, como é explícito nos depoimentos de R5 e R7. Por mais que as escolhas sejam justificadas, a partir de preferências e interesses idiossincráticos, a escolha está associada com as experiências vividas no âmbito familiar e na trajetória escolar (TARDIF, 2014).

Segundo Bourdieu (2012), o acesso ao jogo escolar por parte das categorias sociais até então excluídas, o prolongamento e a obrigatoriedade escolar provocaram mudanças no sistema escolar que acarretaram a intensificação da concorrência e o aumento dos investimentos educativos, principalmente, por parte das camadas médias, que buscam estratégias de manutenção de sua posição no espaço social ou para galgarem posições mais altas. No caso das camadas populares, os investimentos são menores por conta da pouca familiaridade dos mecanismos e dos processos de apreensão do jogo, mas os fazem de acordo com as chances de obterem sucesso na escolarização dos seus filhos, como no prolongamento da escolarização que ultrapasse as suas.

\section{ESTUDANTES E A PERMANÊNCIA NO MEIO ACADÊMICO}

A maioria dos estudantes participantes das entrevistas afirmam que se sentiram acolhidos na Educação Superior. Eles declaram que, a transição do Ensino Médio para o Superior não foi simples.

Apesar de muitos jovens possuírem conhecimento dos programas de nível superior e saberem da importância para a formação acadêmica, o tempo dedicado ao trabalho como forma de sobrevivência impõe, em vários casos, limites acadêmicos, como na participação dos programas internos e fora da universidade, constituindo-se em um obstáculo ao pleno rendimento acadêmico, não sendo a única dificuldade a esses estudantes.

O acesso também é evidenciado como difícil e carregado de anseios. R1 sentiu impacto na adaptação ao habitus da universidade, "visão de mundo diferente, por estar acostumado com ensino médio, o conbecimento que nunca imaginei ter acesso".

Para R2 e R6, o babitus de estudar o ensino médio em escola pública é diferente, "o colégio não exigia muito, aqui tive que estudar para tirar nota". A adaptação para R4 foi a maior dificuldade no início do curso, bem como conseguir conciliar estudo e trabalho. A instituição é muito grande, disse R7 que se sentiu perdida e mal informada no que tange ao local das salas de aula. 
R8 já tinha vivência universitária, mas foi um impacto no primeiro dia de aula em que "o professor mandou estudar um texto difícil de interpretação".

Nesse sentido, fazemos uso das conclusões de Pereira e Felicetti (2015) quanto ao papel do professor no ensino e na aprendizagem de competências, que afirma que o papel deste profissional é uma "mistura de saberes, plasticidade, rigidez, valores, afetos, acolhimento e receptividade ao aluno" (p. 169). Cabe ao professor, diante das falas apresentadas, direcionar um olhar humanizado ao ensino, tendo em vista que o estudante é um ser problematizado, com diferentes matizes, que requerem esforços para que possam aprender e se desenvolver nas diferentes visões de mundo, nas situações apresentadas por R1, R2, R6 e R8. Além disso, segundo Santos e Linhares (2018, p.92) “[ ] o docente deve criar estratégias, para que o estudante possa ser sujeito do processo de aprendizagem."

No mesmo sentido apontam Dorio e Corti (2014), quando afirmam que o processo de inserção dos estudantes na Educação Superior não se configura da mesma forma para todos, em razão da complexidade desses sujeitos. São diversos fatores institucionais, acadêmicos, pessoais e sociais que influenciam nas experiências dos estudantes no seu ingresso. Diante disto, o corpo docente e a instituição são os principais referenciais dos estudantes, tendo o professor um duplo papel: de cativar e recuperar este estudante com metodologias de acordo com suas possibilidades, apresentando desafios para que possa se desenvolver e se relacionar com outros estudantes.

Assim, cabe à IES promover intervenções dirigidas e personalizadas aos estudantes, de forma a compensar eventuais déficits de aprendizagem, fomentando a participação do estudante para assumir o protagonismo sobre seus estudos. Além dessas iniciativas, torna-se necessário fomentar o uso dos serviços institucionais como suporte para a aprendizagem do estudante, promovendo formação docente que habilite esse profissional a compreender as peculiaridades dos estudantes ingressantes nesse grau de ensino (DORIO; CORTI, 2014).

Percebe-se também nas falas dos estudantes que, em grande parte não é suficiente ter o acesso à Educação Superior para que tenhamos assegurada a situação de sucesso escolar. Os programas e as políticas educacionais de inclusão promovem o acesso de estudantes de camadas populares, mas, por outro lado, configuram-se como programas que não garantem a permanência, que fica a cargo das próprias instituições, segundo Catani e Giolli (2005).

$\mathrm{O}$ que os estudantes relatam sobre suas dificuldades refletem suas trajetórias, ainda que bem sucedidas, pois concluíram a educação básica dentro da faixa etária, considerada como ideal. O processo de constituição da hexis e do ethos escolar são frágeis do ponto de vista da exigência acadêmica que relatam. É o que Bourdieu e Passeron (2010) chama de babitus, são os capitais incorporados, sobretudo, o capital cultural que se constitui o elemento da herança familiar que mais 
tem impacto na definição do destino escolar, visto que favorece o desempenho escolar na medida em que facilitaria a aprendizagem, dos códigos veiculados e sancionados pela escola.

Por conta dessas trajetórias marcadas pelo baixo capital cultural herdado, mas com alto nível de aspiração desses estudantes em relação ao prolongamento da escolarização, o investimento escolar parental e as redes de sociabilidade durante o percurso escolar e social possibilitaram aos estudantes a criação de estratégias que lhes permitiram ingressar na universidade. Pode-se inferir também que os estudantes têm percepção da sua condição de grupo e que buscam saídas para as adversidades que se apresentaram no percurso escolar, construindo estratégias de apropriação do campo e de inserção no mundo acadêmico.

Coulon (2017) estuda o processo de constituição do ofício de estudante, o que ele chama de processo de afiliação educacional, mais precisamente ao processo de afiliação à vida universitária. Para ele, a entrada do estudante na educação superior é marcada por três tempos: o tempo de estranhamento, no qual o estudante se depara com um universo desconhecido, bem diferente da instituição escolar da qual fazia parte; depois, ele atravessa o tempo da aprendizagem, uma etapa marcada por adaptações e acomodações progressivas e, por fim, o tempo da afiliação, em que o estudante já compreende as normas e regras institucionais e adquire o status de membro: aprendeu o ofício de estudante universitário. Ou seja, passa da condição de aluno à condição de estudante.

E a esta condição outros aspectos se associam, como por exemplo, o papel do professor na acolhida ao estudante na Educação Superior. Nesse aspecto, Thomas (2008) aponta que estratégias de ensino, aprendizagem e avaliação influenciam na permanência de estudantes na Educação Superior, sejam eles de primeira geração ${ }^{5}$ ou de outros contextos sociais. Com isso, o professor se insere nesse papel como aquele sujeito que adotará metodologias ativas que tornem a aprendizagem relevante ao estudante, engajando-o em seu processo de aprendizagem. O professor, no percurso da aprendizagem dos estudantes, necessita ser um aliado, senão um "companheiro indissociável na aprendizagem [...]” (PEREIRA, FELICETTI, 2015, p. 168). O docente que acolhe o estudante, busca sua participação ativa em aula, gera diferencial na percepção dos alunos. Além disto, cabe à instituição integrar abordagens curriculares que alcancem todos os tipos de estudantes, que se beneficiarão, além de iniciativas de financiamento, como no caso do Vestibular Social em questão.

Dissonante do sentimento de acolhida evidenciado pela maioria dos sujeitos pesquisados, R2 foi a única que afirma ter sofrido discriminação direta por ser bolsista, tendo se sentido

\footnotetext{
${ }^{5}$ Estudante de $1^{\text {a }}$ geração - P-Ger é o primeiro de sua família a buscar educação superior. (TERENZINI et al., 1996; CHOY et al., 2000; RODRIGUEZ, 2003; CHEN; CARROLL, 2005).
} 
diminuída por colegas e professores. A entrevistada afirmou que "os alunos da minha sala que pagam integral questionam o fato deles pagarem integral e eu ter a bolsa de cinquenta por cento e os professores falam que a universidade abre oportunidade para alunos que não tem condições de aprendizagem para estudarem em uma IES". $\mathrm{O}$ apontamento de $\mathrm{R} 2$ denota um aspecto importante das relações estabelecidas na faculdade, cujas interações ocorrem entre: estudantes e instituição; estudante e professor; e estudante e estudante. Esta última interfere na aprendizagem e desenvolvimento dos estudantes, segundo os estudos de Cabrera e La Nasa (2008).

No caminho do estabelecimento dessas relações, Dorio e Corti (2014) apontam que os vínculos sociais são um aspecto decisivo no processo de integração do estudante universitário. Desde o primeiro instante, os estudantes engajam suas competências pessoais e sociais para estabelecer essas conexões, com colegas e professores para melhorar e progredir na vida acadêmica, no processo de transição inicial na universidade.

O percurso formativo desses estudantes pesquisados, antes de ingressar os estudos na Educação Superior, em questão aqui uma IES comunitária, é proveniente da educação básica pública e, a maioria deles chegam cheios de anseios e dificuldades de aprendizagem. As relações didáticas e humanistas dos docentes com o estudante são fatores primordiais para o sucesso acadêmico e profissional do estudante, pois o docente é responsável em sua formação. É aquele que necessita acolher, incentivar e entender o estudante.

\section{CONSIDERAÇÕES FINAIS}

Ao certo, o que podemos afirmar é que, mesmo por meio das políticas de inclusão, o sistema de Educação Superior brasileiro não consegue democratizar as relações que se estabelecem entre acadêmicos, conhecimento e instituição. Consegue-se democratizar o acesso, no entanto, em seu interior continua a reprodução das desigualdades, sejam elas pelo silenciamento acadêmico, pelo rótulo de ser bolsista, pelas diferenças culturais e pelo próprio currículo escolar que, muitas vezes, não atende os anseios, a realidade e as necessidades desses estudantes.

Pudemos constatar que os estudantes do vestibular social tiveram êxito escolar na Educação Básica uma vez que conseguiram finalizar seus estudos dentro da faixa etária correspondente, o que os possibilitou ter acesso à universidade dentro das expectativas de idade ideal prevista nas políticas públicas para a juventude. A escolha da universidade, para a maioria dos estudantes, se deu em razão da possibilidade de bolsa; em segundo lugar, pela credibilidade que a instituição passa, por ser a primeira Universidade no Estado de Goiás. 
Diante dos relatos dos estudantes participantes da pesquisa é perceptível que o acesso à Educação Superior não é a única garantia do sucesso escolar. As IES necessitam, além de programas de permanência e acompanhamento durante toda trajetória escolar ao estudante, criar mecanismos capazes de identificar e/ou associar as particularidades dos ingressantes com a escolha do curso, bem como oportunizar formação continuada para os docentes com temáticas que os sensibilize a melhor entender o novo perfil estudantil que permeia o campus.

Salientamos que as redes de relações docente e discente são pilares para a permanência do estudante, e podem contribuir para formação acadêmica e profissional. No processo de aprendizagem, a interação do professor-aluno e de suma importância para que ocorra o sucesso no transcorrer do curso, pois, segundo Freire (1989), o educador e o educando são sujeitos do processo educativo, ambos crescem juntos nessa perspectiva.

É preciso também destacar que a trajetória universitária desses estudantes é marcada por problemas sociais e familiares que impactaram na permanência, por isso, onde alguns foram obrigados a trancar o curso e com isso atrasando a conclusão.

Assim, perante o que foi aqui discutido, evidencia-se a importância das políticas de inclusão, em nosso caso, as que se referem à educação superior, especificamente o Vestibular Social realizado na PUC Goiás. Essas se tornaram efetivamente espaço de inserção e de oportunidade para muitos estudantes pertencentes às camadas denominadas populares, uma vez que a condição econômica é desfavorável.

A ação afirmativa em si não é garantia de inserção no mercado de trabalho ou mesmo de conclusão do curso, porém é uma facilitadora a esses estudantes no seu percurso acadêmico e profissional. Apesar de todos os obstáculos e dificuldades, esses sujeitos pesquisados entendem que a educação é fator importante para seu futuro e para a melhoria de suas condições de vida.

\section{REFERÊNCIAS:}

AMADO, Wolmir Therezio. Entrevista concedia a Gilza Carla Temoteo Melo. Goiânia, 22 jan.2019.

BECK, Ulrich. O que é a globalização? Equívocos do globalismo respostas à globalização. São Paulo: Paz e Terra, 1999.

A Política na Sociedade de Risco. Ideias, Campinas, n.1, 2010. Tradução de Estevão
Bosco.
Revisão
de
AnishaVetter.
Disponível
em: 
< https://periodicos.sbu.unicamp.br/ojs/index.php/ideias/article/view/8649300/15855>.

Acesso em: 21 ago. 2019.

BOURDIEU, Pierre. Introdução a uma sociologia reflexiva. In: BOURDIEU, Pierre. O Poder Simbólico. 10. ed. Rio de Janeiro: Bertrand Brasil, 2007.

Pierre. Sobre o poder simbólico. Trad. Fernando Tomaz. Rio de Janeiro: Bertrand Brasil, 2001.

BOURDIEU, Pierre; PASSERON, Jean-Claude. Los herederos: los estudiantes y la cultura. Buenos Aires Siglo Veintiuno Editores, 2010.

BRASIL. Ministério da Educação. Plano Nacional de Educação 2001-2010. Lei nº 010172, de 9 de janeiro de 2001, que aprova o Plano Nacional de Educação (PNE) e dá outras providências. Brasília: Câmara dos Deputados, Edições Câmara, 2001.

CABRERA, F. Alberto; LA NASA, Steven M. Classroom Teaching Practices: Ten Lessons Learned. In: AUDY, Jorge Luis Nicolas; MOROSINI, Marilia Costa (Orgs.). Inovação e qualidade na Universidade = Innovation and quality in the University. Porto Alegre: EDIPUCRS, 2008. p. 15-74.

CARVALHO, Rose Almas de; SIQUEIRA, Romilson Martins. El compromiso de la PUC Goiás con la calidad de la formación de profesores: la experiencia del examen vestibular social (examen de admisión para estudiantes de escasos recursos). In: UNESCO. La Responsabilidad Social de las Universidades: Implicaciones para américa Latina y el Caribe. Puerto Rico,2015. Disponível em: Acesso em 20 jan.2019.

CATANI, Afrânio; OLIVEIRA, João F. de. Educação Superior. 2001. Disponível em. Acesso em 10 mar. 2017.

CATANI, Afrânio Mendes; GILIOLI Renato de S. Prouni na encruzilhada: entre a cidadania e a privatização. Linhas Críticas, Brasília, v. 11, n. 20, p. 55-68, jan./jun. 2005 
CAVALCANTE, Cláudia Valente. Políticas de ação afirmativa na educação superior brasileira: uma análise dos planos nacionais de educação 2001-2010 e 2014-2024 - uma estratégia para a redução das desigualdades sociais e escolares? Poiésis, Tubarão, v. 9, n. 16, p. 333-350, jul./dez. 2015.

CHEN, Xianglei; CARROLL, C. Dennis. First-generation students in postsecondary education: a look at their college transcripts. Postsecondary Education Descriptive Analysis Report. NCES 2005-171, 2005.

CHOY, Susan P.; HORN, Laura J.; NUÑEZ, Anne-Marie; CHEN, Xianglei. Transition to college: what helps at-risk students and students whose parents did not attend college. New Directions for Institutional Research, v. 27, n. 3, p. 45-63, 2000.

COULON, Alain. O ofício de estudante: a entrada na vida universitária. Educ. Pesqui., São Paulo, v. 43, n. 4, p. 1239-1250, out./dez., 2017.

CRAIDE, Sabrina . Pesquisa mostra queda no interesse por cursos de licenciatura. Revista Agencia Brasil Educação. Brasília.2018. Disponível em : https://agenciabrasil.ebc.com.br/educacao/noticia/2017-11/pesquisa-mostra-queda-nointeresse-por-cursos-de-licenciatura, acesso em : Fevereiro de 2018.

DORIO, Imma; CORTI, Franciele. El primer año en la universidad. La experiencia de los estudiantes. In: FIGUERA GAZO, Pilar (org.). Persistir com éxito en la universidad: de la investigación a la acción. Espanha: Laertes, 2014.

FELICETTI, Vera L. Comprometimento do estudante: um elo entre aprendizagem e inclusão social na qualidade da Educação Superior. 2011. 298 f. Tese (Doutorado em Educação) - Pontifícia Universidade Católica do Rio Grande do Sul. Rio Grande do Sul. 2011.

FELICETTI, Vera Lucia; FOSSATTI, Paulo. ALUNOS PROUNI E NÃO PROUNI NOS CURSOS DE LICENCIATURA: Evasão em foco. Educar em Revista, n. 51, p. 265-282, jan./mar. 2014. Editora UFPR (ISSN: 0104-4060) Disponível em: <http://ojs.c3sl.ufpr.br/ojs2/index.php/educar" http://ojs.c3sl.ufpr.br/ojs2/index.php/educar>. $<$ http://www.scielo.br/pdf/er/n51/n51a16.pdf> 
FREIRE, P. Educação como prática da liberdade. 19 ed. Rio de Janeiro: Paz e Terra, 1989.

GOMES, Kelly Amorim. Indicadores de permanência na educação superior: o caso da disciplina de cálculo diferencial e integral I.2015. Dissertação (Mestrado em Educação). Universidade LA SALLE, Canoas-RS.

LLOYD, Christina. Inovação e Qualidade na Educação a Distância na Universidade Aberta, RU. In. Inovação e Qualidade na Universidade. Audy, Jorge Luis Nicolas; MOROSINI, Marilia Costa. Porto Alegre: EDIPUCRS, 2008.

MANTOAN, Maria Teresa Eglér. Inclusão, diferença e deficiência: sentidos, deslocamentos, proposições. São Paulo: Moderna, 2003.

MARTINS, Carlos Benedito. A Reforma Universitária de 1968 e a abertura para o Ensino Superior privado no Brasil. Revista Educação e Sociologia. Campinas, vol. 30, n. 106, p. 15-35, jan./abr. 2009.Disponível em: <<http://www.scielo.br/pdf/es/v30n106/v30n106a02>>, acesso em : 20 de janeiro de 2018.

MELO, Gilza Carla Temoteo. ACESSO, PERMANÊNCIA E PERSPECTIVAS DE FUTURO: OS ENFRENTAMENTOS DOS (AS) ESTUDANTES DO VESTIBULAR SOCIAL DA PUC GOIÁS. 2019. Dissertação (mestrado em Educação). Pontifícia Universidade Católica de Goiás, Goiânia.

NALIN, Jaime Antônio. A educação superior na formação do professor em exercício na educação básica pública: um estudo de caso do benefício do Prouni. 2018. Tese (Doutorado em Educação). Universidade LA SALLE, Canoas-RS.

PEREIRA, Marcelo Almeida de Camargo; FELICETTTI, Vera Lucia. Professor e Aprendizagem: Perspectivas Discentes. In: ENGERS, Maria Emília Amaral; MOROSINI, Marília Costa; FELICTTI, Vera Lucia. (Orgs.) Educação superior e aprendizagem = Higher. Porto Alegre: EDIPUCRS, 2015. 
RODRIGUEZ, Sandria. What helps some first-generation students succeed? About Campus, v. 8, n. 4, p. 17-22, 2003.

RESENDE, Tânia de Freitas; NOGUEIRA, Cláudio Marques; NOGUEIRA, Maria Alice. Escolha do estabelecimento de ensino e perfis familiares: uma faceta a mais das desigualdades escolares. Educ. Soc. [online]., v. 32, n. 117, p. 953-970, 2011. ISSN 0101-7330.

SANTOS, Nathan. Baixa procura por licenciaturas exige sérias medidas. Revista Leia Já, São Paulo,2018. Disponível em : <https://www.leiaja.com/carreiras/2018/06/29/baixa-procura-porlicenciaturas-exige-serias-medidas/> . acesso em : 25 de janeiro de 2019.

SANTOS, Aryane Raysa Araújo dos; LINHARES, Danillo Moretti Godinho. Reflexões sobre o papel do professor e do estudante na educação a distância. Cadernos Cajuína, V. 3, N. 1, 2018, p. 87 - $99 . \quad$ Disponível em: https://cadernoscajuina.pro.br/revistas/index.php/cadcajuina/article/view/191/142 Acesso em 20 de jan. 2021.

SEVERINO, Antônio Joaquim. Metodologia do trabalho científico. São Paulo: Cortez, 2016

TARDIF, Maurice. Saberes docentes e formação profissional. Petrópolis, RJ: Vozes, 2014.

TERENZINI, Patrick T; SPRINGER, Leonard; YAEGER, Patricia M.; PASCARELLA, Ernest T.; NORA, Amaury. First-generation college students: characteristics, experiences, and cognitive development. Research in Higher Education, v. 37, n. 1, p. 1-22, 1996.

TINTO, Vincent. Leaving College: Rethinking the Causes and Cures of Student Attrition. Chicago: University of Chicago Press, 1993, 2. ed.

TINTO, Vincent. Completing College Rethinking Institution Action. Ed. UChicago Press: Chicago USA., 2012

THOMAS, Liz. Learning and teaching strategies to promote student retention and sucess. In: CROSLING, Glenda; THOMAS, Liz; HEAGNEY, Margaret. Improving student retention in higher education. The role of teaching and learning. Estados Unidos: Routledge, 2008. 
ZAGO, Nadir. Do acesso à permanência no ensino superior: percursos de estudantes universitários de camadas populares. Revista Brasileira de Educação, São Paulo, v. 11, n. 32, p. 226-236, maio/ago. 2006 